\title{
Online Social Presence "OSP" Patterns Correlation with Students' Academic Performance among Master of Education Program Students
}

\author{
Yahya M. Al-dheleai
}

Senior Lecturer, School of Educational Studies, Universiti Sains Malaysia, Malaysia, yamohd3@gmail.com

\section{Zaidatun Tasir}

Prof., School of Education, Faculty of Social Sciences and Humanities, Universiti Teknologi Malaysia, Malaysia, p-zaida@utm.my

More social presence in online learning environment was seen to be one of the important predictors of students' academic performance. However, patterns of students' Online Social Presence (OSP) when using social networking tools for learning has not been widely discussed in previous studies. Therefore, this study was aimed to investigate the patterns of students' OSP. Moreover, this study aimed to find which patterns of students' OPS that correlated to their Academic Performance (AP). The investigated patterns of OSP are Social Respect (SR), Social Sharing (SS), Open Mind (OM), Social Identity (SI) and Intimacy (I). The quantitative methods of data collection and data analysis were used in this study. The data were collected from 65 students in one of Malaysian Public Universities. OSP Questionnaire (OSPQ) was adopted to collect the required data. The data were analyzed using SPSS software to find mean, standard deviation for each pattern of students' OSP. Moreover, Pearson's Correlation Coefficient was used to analyze the correlation between each pattern of students' OSP and AP. The findings of this study showed that all patterns of OSP were highly perceived by the respondents of the study. Moreover, Pearson's Correlation Coefficient outcome showed high and significant correlation between SR, SS, OM and SI with students' AP while the correlation between Intimacy and AP was low.

Keywords: online social presence, social respect, social sharing, open mind, social identity, intimacy, academic performance

\section{INTRODUCTION}

OSP was defined as "the degree of person to person awareness, which occurs in the computer environment" (Tu, 2002), and as "the degree to which a person is perceived as a 'real person' in mediated communication" (Gunawardena \& Zittle, 1997). However,

Citation: Al-dheleai, Y. M., \& Tasir, Z. (2020). Online Social Presence "OSP" Patterns Correlation with Students' Academic Performance among Master of Education Program Students. International Journal of Instruction, 13(2), 493-506. https://doi.org/10.29333/iji.2020.13234a 
Sung \& Mayer (2012) considered OPS as students' subjective perception of being connected with others in online environments. Educationally, OPS is the level of connectedness among course participants (Instructor and students) that reflected through their motivation to take an active role in their own learning process (Whiteside, Dikkers \& Lewis, 2014). Therefore, OSP found to be an effective factor for students' learning and their academic performance (Joksimović, Gašević, Kovanović, Riecke, \& Hatala, 2015). For its importance, many studies had investigated the effect of OSP on students learning and performance. However, a little is found about the relationship between certain types of OSP and students' academic performance. Hence, this study is an effort to add new findings to the OSP literature through investigating the relationship between the types of OSP "SR, SI, SS, OM and I" with students' AP.

\section{OSP and Education}

Research in education confirmed that students engage in learning when they feel connected with others and when they play an active role in their learning process. Therefore; OSP considered to be an important component of the effective learning either in face-face or in the online learning environment. It is also considered as the description of the relationship and connection with others (Irwin \& Berge, 2006) and the value of interaction in online learning due to its ability to establish a sense of presence in virtual environment (Valenzuela, Fisher, Whale \& Adapa, 2013).

Without social presence, students feeling of isolation could be increased (Wheeler, 2007). Social presence can be noted in an environment where students are challenging notions through peer interactions where the instructor is facilitating the lines of inquiry; students may feel connected together as a community, and the goal of authentic learning in the online environment is quite possible (Becker, 2012). Richardson and Swan, (2003) stated that several studies found that social presence has a great impact especially on students' online learning. Additionally, social presence was found to be the predictor of learning satisfaction (Richardson, Maeda, Lv \& Caskurlu, 2017) Therefore, the purpose of generating social presence in online environment is to establish a level of comfort when students' feel easy to connect with the instructor and peers (Aragon, 2003). Hence, those findings indicate that social presence is an important construct in investigating students' online learning experience (Cui, 2013) as it is considered as an essential for establishing online collaborative and constructive learning approach (Garrison, 2011). However, there are a lack of studies that investigated the relationship between certain patterns of social presence and students' performance.

\section{Online Social Presence "OSP" and Students' Academic Performance "AP"}

Social presence in online learning environment appeared to be a predictor of students learning outcome (Richardson \& Swan, 2003). A study conducted by Picciano (2002) found that students with high perception of social presence achieved higher scores in actual test and written assignment than medium and low social presence perception groups. Picciano (2002) examined performance in an online course and its relation to student interaction and sense of presence in the course. The findings of the study showed that the relationship between students perception of social presence and the written 
assignment was statistically significant, while the relationship between student perception of social presence and the examination was not significant. Furthermore, instructor presence and interaction with students were positively related to student learning and motivation (Baker, 2010). For example, when students have a strong relationship with their instructors they will believe more in their instructors and more motivated to be involved in the learning process (Ilias \& Nor, 2012) and of course that would be reflected in their academic performance. This is supported by Wei \& Chen (2012) claim that social presence has a significant impact on learning interaction, which in turn has significant effects on learning and academic performance (Zhan \& Mei, 2013). Largely, Richardson et al. (2017) conducted a meta-analysis for studies that conducted between 1992 and 2015 with focus on studies that reported the relationship between social presence and students' satisfaction and perceived learning. Researchers' meta-analysis concluded that students' perceived learning was very well predicted through social presence (Richardson et al., 2017). However, the current study delved to to find out the relationship between specific OSP patterns and students' AP.

\section{THEORETICAL FRAMEWORK}

Figure 1 show the proposed model of OSP patterns and students' AP. The patterns namely are Social Respect (SR), Social Sharing (SS), Open Mind (OM) Social Identity (SI), and Intimacy (I). The definitions of the included patterns are detailed in this section respectively.

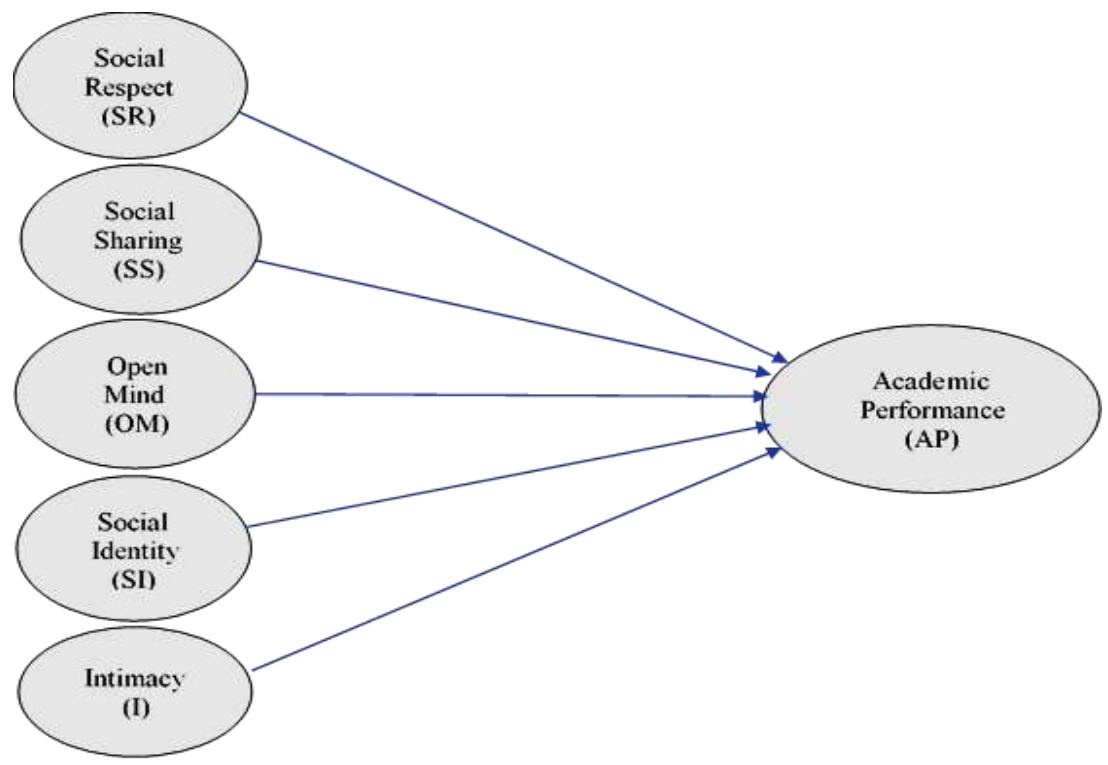

Figure 1

OSP and AP Theoretical Framework 


\section{Social Respect (SR)}

SR is about students' feeling that they are respected by the instructor and peers through appreciating and acknowledging their questions, ideas, opinions or points of view. Timely response and the use of humor either by peers or by the instructor give students the sense of presence as this action support their' feeling that they are socially respected by others. Moreover, students feel they are socially respected when they can strike up communication and have conversation with the instructor and other students which result more sense of social presence (Sung \& Mayer, 2012). Garrison et al. (2000) considered the use of humor as contributive to social presence and learning. Gorham, \& Christophel (1990) linked the use of humor to more conversation as it decreases the social distance among participants. Eggins \& Slade (2005) argued that the humor and joking is the way to build group cohesion with critical discourse which presents group differences without affecting the group consensus and similarity. Therefore, the use of humor according to them is similar to the invitation to strike up conversation with the instructor and other participants (Gorham, \& Christophel, 1990) and timely response which in turn give students the sense that they are socially respected (Garrison, et al., 2000).

\section{Social Sharing (SS)}

SS is the acts that strengthen students-instructor and peers' social relation in a way that enhance students' learning success through sharing learning information with others and expressing their values and beliefs. Moreover, the encouragement that offered by the instructor and peers in the online learning environment is seen as the motive for students to study hard. Therefore, students tend to highly appreciate the close relationship with instructor and peers (Sung \& Mayer, 2012). Yildiz (2009) argued that participants ability to express their values, believes and attitude, share information and to talk about their native culture reflect the level of their social presence. The researcher considered sharing values and believe as part of the affective indicators of social presence (Yildiz, 2009). Moreover, expressing interpersonal support, encouragement and acceptance of shared opinions and values promote more meaningful social interaction that reflect the participant's social presence (Rourke, Anderson, Garrison, \& Archer, 2001).

\section{Open Mind (OM)}

$\mathrm{OM}$ is about discussing student's idea, expressing agreement or disagreement in a constructive way which is reflected in students' ability to express their emotion, feelings and ideas with providing positive feedback about others' opinions or ideas (Sung \& Mayer, 2012). Therefore, providing online atmosphere that allows students to freely express their feedback and opinions will inculcate students to be more open to accept different point of view. Open Mind has the elements of open communication which was defined as reciprocal and respectful exchange. Open communication include mutual awareness and respect of each other's' contribution (Garrison et al., 2000). Mutual awareness according to (Garrison et al., 2000) is concerned with respectful respond and impression management about others' comments and contribution which lead to group cohesion. 


\section{Social Identity (SI)}

SI is about recognizing the existence of others through greeting them in the posts or messages and addressing their names. Moreover, starting the instructor and students discussion and posts with greetings posts is an effective strategy to foster students' sense of presence. Additionally, addressing participant's name reflect that the instructor and peers are aware of his/her identity and she/he is recognized and known person in the learning community (Sung \& Mayer, 2012). Therefore, recognizing student social identity by peers and instructor is essential for fostering students' sense of presence during online interaction. Social identity based of Sung \& Mayer (2012) has the characteristics of cohesive response that defined by (Rourke et al., 2001) which include phatic, salutation, vocatives and addressing group as we, us and ours. Phatic expressions serve to confirm group unity and cohesiveness. However, vocative is expressed through addressing participant by name to show he/she is known by the instructor and other participants which in turn establish closer relationship. Moreover, inclusive pronouns such as we, us and our establish the sense of closeness and association among learning community members (Rourke et al., 2001).

\section{Intimacy (I)}

Intimacy is about sharing personal life stories, emotion and feelings with other learning participants. It reflects the deeper relationship and high sense of safety and trust toward the instructor and other participants. When students engage in intimacy feeling they seems to be willing to disclose more personal life stories and feel better when he/she share emotions with online learning community members (Sung \& Mayer, 2012). Intimacy is part of emotional expressions that reflected through self-disclosure which contribute to social presence (Garrison et al., 2000). One way of Self-disclosure is sharing feelings which indicate the level of trust and closeness among learning participants. Moreover, sharing personal information and stories was categorized as a type of affective responses which reduce participants feeling of social isolation and contribute to forming individualized impressions of interlocutor (Rourke et al., 2001).

\section{Academic Performance (AP)}

Academic performance in this study refers to students perceived academic performance that measured through the given survey items. Students' perceived academic performance is a subjective estimation of what student believe he/she has learnt or achieved (Papamitsiou \& Economides, 2014). Perceived performance is an indicator of students' satisfaction of what they believe they attained from the targeted achievement based on their efforts for understanding and knowledge acquisition (Papamitsiou \& Economides, 2014). Students' perceived academic performance in this study was measured using 4 survey items. Examples of AP items is shown in the methodology section.

\section{Objectives}

This study aims to identify the following: 
i. To find out students perceived Online Social Presence "OSP" in course-related interaction

ii. To analyze the correlation between each pattern of students online social presence and their academic performance.

\section{METHOD}

In the academic year of 2015/2016, Master of education program students from one of the public universities in Malaysia were exposed to online interaction that took place for course-ware development course. Online interaction allowed interaction and discussion about the course content and sharing learning resource among students and with the instructor. To point out, this article is part of a large-scale study where the focus here is on analyzing quantitative data to measure online social presence among students. Random sample sampling technique was applied during questionnaire data collection where every member of the population has the chance to be selected. The population of this study is 79 students who enrolled in the Master of Education program at the time of conducting this study. Therefore, questionnaire was distributed among the targeted population members to collect their responses about their social presence during online interaction throughout the semester. However, 65 questionnaires were collected from the total number of the respondents. The ratio of the number of the respondents to the total population is 1: 1.21 which indicate that $82.28 \%$ of the population responded to the questionnaire. SPSS statistics software was used to analyze the data of this study.

\section{Instrument}

In this study, the researchers adopted Online Social Presence Questionnaire (OSPQ) developed by (Sung \& Mayer, 2012) to measure students' perceived OSP in courserelated interaction. The five-point Likert scales questionnaire consist a total of 23 items that distributed among six subscales. While OSPQ was used to measure five OSP subscales (SR, SS, OM, SI and I. Dependent variable items were developed by the researchers to measure students perceived academic performance. Examples of students perceived academic performance are "Interaction with the instructor enhance my academic performance", and "Interaction with other students enhance my academic performance". The instrument has gone through validity check by two academic experts in the field, some amendments has been done according to the experts' comments. Moreover, reliability test has been done to the data collection instrument to find out the level of internal consistency of the instrument. The findings of the reliability test showed that the questionnaire has high internal consistency level with Cronbach's Alpha as shown in table 1. Reliability test findings show that the used instrument is highly reliable to be used measure the contribution of this study to find the correlation between each pattern of OSP and students perceived academic performance (AP). 
Table 1

Reliability Statistics Value

\begin{tabular}{lll}
\hline Reliability Statistics & & \\
\hline Pattern Name & Cronbach's Alpha & N of Items \\
\hline SR & .846 & 5 \\
SS & .882 & 5 \\
OM & .826 & 3 \\
SI & .788 & 4 \\
I & .935 & 2 \\
AP & .935 & 4
\end{tabular}

* Social Respect (SR), Social Sharing (SS), Open Mind (OM),

Social Identity (SI), Intimacy (I). Academic Performance (AP)

\section{Data Analysis}

The respondents' level of OSP during online interaction was analyzed through descriptive analysis by finding the Mean and Standard Deviation of each item. However, Pearson Correlation Coefficient was used to find out the correlation between each OSP pattern and students' AP.

\section{FINDINGS}

\section{Students' perceived Online Social Presence "OSP" in course-related interaction}

The findings illustrated in table 2 revealed that apart from intimacy pattern, students generally expressed high perception about all OSP patterns. The following statements report the items with highest Mean for each OSP pattern. For example, SR3 which measure instructor or peer's timely response to student's question or idea is the best encouraging action for student's sense of social respect with Mean of 4.43 and SD of .585. Besides, SS2 show that sharing learning information is the action that promotes students sense of social sharing in the online environment with Mean of 4.32 and SD .663. Mostly, students highly expressed that they have the sense social sharing in the online learning environment. Similarly, OM2 reveal that higher students' perception in this construct is related to receiving a positive feedback from peers and instructor about their idea, opinion and point of view with Mean of 4.32 and SD .533. Overall, instructor and peers open mind practice during online interaction seen as a positive motivation for their feeling of sense of presence. Interestingly, like SS2 and OM2, SI4 with Mean of 4.32 and SD .503 showed that the respondents of this study believe that their level of presence was high when instructor or peers call her/him by name. Generally, students expressed a positive perception about the role of social identity practice on their level of presence during online interaction. Nevertheless, unlike other OSP items, I2 indicated students moderate believe that sharing their emotions and feelings with learning community can enhance their level of presence in online interaction with Mean of 3.69 and SD 1.059. Therefore, intimacy appeared as the least pattern to enhance students' level of presence during online interaction. More details about entire OSP items findings of means and SD are shown in table 2. 
Table 2

Students' Online Social Presence

\begin{tabular}{llll}
\hline Item No & Item Code & Mean & Std. Deviation \\
\hline 1 & SR1 & 4.35 & .570 \\
2 & SR2 & 4.40 & .632 \\
3 & SR3 & 4.43 & .585 \\
4 & SR4 & 4.27 & .573 \\
5 & SR5 & 4.33 & .566 \\
6 & SS1 & 4.06 & .807 \\
7 & SS2 & 4.32 & .663 \\
8 & SS3 & 4.23 & .655 \\
9 & SS4 & 4.16 & .719 \\
10 & SS5 & 4.23 & .655 \\
11 & OM1 & 4.24 & .531 \\
12 & OM2 & 4.32 & .533 \\
13 & OM3 & 4.21 & .544 \\
14 & SI1 & 4.16 & .626 \\
15 & SI2 & 4.04 & .623 \\
16 & SI3 & 4.01 & .649 \\
17 & SI4 & 4.32 & .503 \\
18 & I1 & 3.64 & 1.022 \\
19 & I2 & 3.69 & 1.059 \\
$*$ Social Respect (SR), Social Sharing (SS), Open Mind (OM), \\
Social Identity (SI), Intimacy (I)
\end{tabular}

The Correlation between OSP Patterns and AP.

Pearson correlation coefficient was run to determine the relationship between five patterns of students' online social presence and their perceived academic performance. The findings respectively illustrated in table 7 showed that there were positive and significant relationship between Social Respect (SR) and Academic Performance (AP) ( $\mathrm{r}$ $=.375, \mathrm{n}=65, \mathrm{p}=.002$ ), positive and significant relationship between Social Sharing (SS) and $\mathrm{AP}(\mathrm{r}=.569, \mathrm{n}=65, \mathrm{p}=.000)$, positive and significant relationship between Open Mind $(\mathrm{OM})$ and AP $(\mathrm{r}=.547, \mathrm{n}=65, \mathrm{p}=.000)$, positive and Significant relationship between Social Identity $(\mathrm{SI})$ and AP $(\mathrm{r}=.473, \mathrm{n}=65, \mathrm{p}=.000)$. However, Pearson's correlation showed that there no statistically significant relationship between Intimacy (I) and AP $(r=.319, \mathrm{n}=65, \mathrm{p}=.010)$. In general, the findings indicated that, except intimacy (I) pattern, social presence patterns have positive and statistically significant correlation with students' academic performance which means that the more students' sense of certain SP pattern the higher they perceive their academic performance AP. 
Table 3

Pearson Correlation for Each SP Pattern and AP

\begin{tabular}{|c|c|c|c|c|c|c|c|}
\hline & & SR & SS & $\mathrm{OM}$ & SI & I & AP \\
\hline Social Respect & Pearson Correlation & 1 & $.581^{* *}$ & $.627^{* 2}$ & $.460^{* *}$ & .085 & $.375^{* *}$ \\
\hline \multirow[b]{2}{*}{ (SR) } & Sig. (2-tailed) & & & .000 & .000 & .499 & .002 \\
\hline & $\mathrm{N}$ & & & 65 & 65 & 65 & 65 \\
\hline \multirow[t]{3}{*}{ Social Sharing } & Pearson Correlation & & 1 & $.616^{* *}$ & $.547^{* *}$ & $.333^{* *}$ & $.569^{* *}$ \\
\hline & Sig. (2-tailed) & & & & .000 & .007 & .000 \\
\hline & $\mathrm{N}$ & & & & 65 & 65 & 65 \\
\hline \multirow[t]{3}{*}{ Open Mind } & Pearson Correlation & & & 1 & $.637^{* * *}$ & $.300^{*}$ & $.547^{* *}$ \\
\hline & Sig. (2-tailed) & & & & & .015 & .000 \\
\hline & $\mathrm{N}$ & & & & & 65 & 65 \\
\hline \multirow[t]{2}{*}{ Social Identity } & Pearson Correlation & & & & 1 & $.455^{* *}$ & $.473^{* *}$ \\
\hline & Sig. (2-tailed) & & & & & & .000 \\
\hline \multirow{2}{*}{$\frac{(\mathrm{SI})}{\text { Intimacy }}$} & $\mathrm{N}$ & & & & & & 65 \\
\hline & Pearson Correlation & & & & & 1 & $.319^{* *}$ \\
\hline \multirow[b]{2}{*}{ (I) } & Sig. (2-tailed) & & & & & & .010 \\
\hline & $\mathrm{N}$ & & & & & & 65 \\
\hline
\end{tabular}

**. Correlation is significant at the 0.01 level (2-tailed).

*. Correlation is significant at the 0.05 level (2-tailed).

\section{The Outcome OSP and AP Correlation}

Figure 2 depict the outcome of OSP and AP Pearson Correlation Coefficient which indicate significant correlation between SR, SS, OM and SI with AP. However, the correlation between Intimacy (I) and AP was found to be hardly and slightly significant.

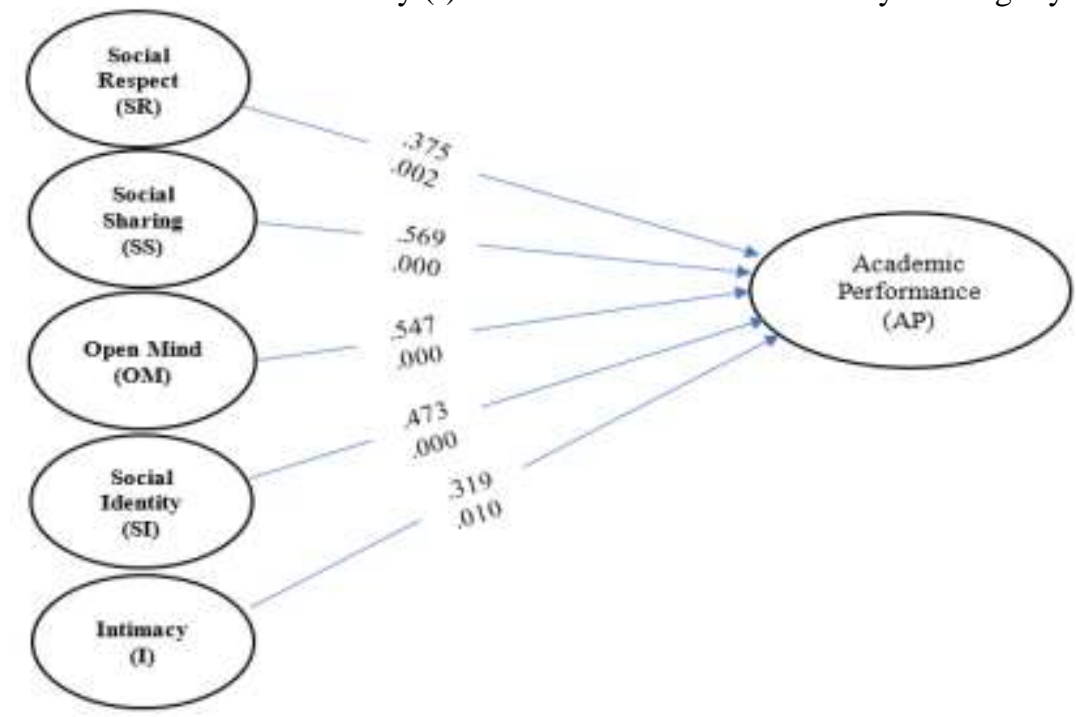

Figure 2

OSP Patterns with Significant Relationships with AP 


\section{DISCUSSION}

The findings of this study revealed that students expressed high level of OSP. Moreover, OSP patterns found to be an important factor to improve students' AP. The following paragraphs were devoted for discussing students' perception about the role each single pattern on the level of OSP and its correlation with AP.

Social respect findings illustrated that; students feel higher level of social presence in online learning environment when they are more respected. Therefore, instructors are required to play an active role in establishing social presence through showing respect to students' ideas, point of views, efforts and participation in his/her posts and messages. Instructor also should encourage students to freely communicate with each other and with him/her as well. As a result, students will engage in more discussion as they feel their efforts are valued by the instructor and other participants. Likewise, social sharing findings suggest that, instructor and students need to share their information in a way that strengthens their social relation (Sung \& Mayer, 2012). Social relation can be also achieved through respecting others' values and beliefs and providing support to students who face difficulties in their study and in their personal life as well. However, the mentioned acts will certainly lead to close relationship between instructor and students and among students through which students' learning and performance would be improved.

The findings of open mind construct indicated that students prefer the open environment that allows them to express their emotion, opinion and ideas. Moreover, students are open to others feedback and discussion about their opinion or ideas and they even welcome others to disagree with their opinion in a way that enrich the discussion and add other aspects to the discussed topic. Therefore, instructor and students need to show open mind that allow critical discourse and let students freely state their feedback to facilitate cognitive interaction in online environment (Sung \& Mayer, 2012). Besides, to promote students' sense of social identity, this study suggests that instructor needs to be aware of students' identity so that they feel he/she care about them. Similarly, peers are required to show their awareness of each other's identity and inject greetings statements and addressing others by names to raise the sense of learning community connectedness.

Unlike other patterns, the findings revealed that student still more conservative and not highly willing to share their personal life stories and emotions with others. The findings reflect that students still perceive limitations of their openness and to some level unwilling to share personal life details with the instructor and peers. In this case, instructor needs to boost students' sense that they are safe with establishing the sense of trust among the learning community. Instructor need to make students aware that they may share the experience that connected to their study and to be careful about sharing sensitive personal stories (Al-dheleai \& Tasir, 2019).

Generally, the findings of this study confirmed that social presence is related to academic performance. These findings are in line with previous studies which reported that social presence is connected to students learning (Picciano, 2002; Zhan, Z., \& Mei, H., 2013; Richardson et al., 2017). The significant correlation between social presence 
patterns and academic performance as shown in this study can be attributed students' openness towards the instructor and peers, shared respect, information sharing and acknowledging the existence of all members in the learning community. In the socialized environment, students can openly ask questions and seek help from the instructor and peers as they feel connected and will receive timely response from them. In such environment, students also receive support and encouragement from others which can motivates them to study harder. Comparably, Christophel (1990) found that teachers immediacy that reflect teachers' social presence improve students motivation to learn. Furthermore, this study findings is supported by (Short, Williams, \& Christie, 1976) which indicate that social presence is the key of understanding person-to-person communication that occurs in the social context. Understanding others help students to establish more collaboration and feel free to seek assistance to overcome the difficulties and achieve better academic performance. Thus, social presence is essential for better instruction in traditional and in the online learning environment (Gunawardena, 1995).

However, the low correlation between intimacy and academic performance could be connected to notions that this type of feeling is more personal and not related to learning context. It is important to realize that the cultural effect in the context of this study might influence respondents perceived intimacy level. This argument is supported by the fact that students' perception about intimacy reported in this study achieved the lowest mean compared to other patterns. It seems that sharing personal life stories and emotions in most of the respondents understanding is something shouldn't be shared with learning community members as it is not related to the learning activities and discussions.

\section{CONCLUSION}

This study was conducted to investigate students' perception about several online social presence patterns after they gone through online course-related interaction. This study also analyzed the relationship between each OSP pattern and AP. The findings of this study showed that students have high perceived level of OSP. Moreover, exception intimacy pattern, social presence pattern showed high statistically significant correlation with students perceived academic performance. These findings confirm that social presence is a predictor factor students' learning and academic performance.

\section{RESEARCH IMPLICATION}

Based on our findings, instructional designers and instructors need to give high consideration for fostering students' academic performance through facilitating instructor and students' online social presence. Social presence is the factor that allow students to comfortably interact with the instructor and peers in online environment. Moreover, students' sense of social presence was considered as a motivator for students to work hard in their study and to achieve better academic performance. 


\section{LIMITATION AND FUTURE WORK}

This study has several limitations which open a new question and open a new prospect for future research. This study was limited to students in education field and the focus was only on students' perception. Additionally, this study examined social presence patterns in relation to students perceived academic performance and not with assessed exams or project. However, future studies are recommended to include respondents from difference faculties including instructors. Furthermore, researchers are recommended to analyze the content of student and instructor online discussion to find out how social presence expressions are depicted during online discussion. Lastly, future studies are recommended to investigate the correlation between students' use of social presence expressions during online discussion and course assessed exams or projects.

\section{DECLARATION OF CONFLICTING INTEREST}

The author(s) declared no potential conflicts of interest with respect to the research, authorship, and/or publication of this article.

\section{ACKNOWLEDGEMENT}

The authors would like to thank the Universiti Teknologi Malaysia (UTM) and Ministry of Education (MoE) Malaysia for their support in making this project possible. This work was supported by the Research University Grant (Q.J130000.2410.04G79) initiated by UTM and MoE.

\section{REFERENCES}

Al-dheleai, Y. M., \& Tasir, Z. (2019). Web 2.0 for fostering students' social presence in online learning-based interaction. Journal of Technology and Science Education, 9(1), $13-19$.

Aragon, S. R. (2003). Creating social presence in online environments. New Directions for Adult and Continuing Education, 2003(100), 57-68.

Baker, C. (2010). The Impact of instructor immediacy and presence for online student affective learning, cognition, and motivation. Journal of Educators Online, 7(1), n1.

Becker, D. H. (2012). Online social interaction, Web 2.0 and social presence: A case study (Unpublished doctoral dissertation). Northern Arizona University.

Christophel, D. M. (1990). The relationships among teacher immediacy behaviors, student motivation, and learning. Communication Education, 39(4), 323-340.

Cui, G. (2013). Evaluating online social presence: An Overview of social presence assessment evaluating online social presence. Journal of Educational Technology Development and Exchange, 6(1). https://doi.org/10.18785/jetde.0601.02.

Eggins, S., \& Slade, D. (2005). Analysing casual conversation. Equinox Publishing Ltd.

Garrison, D. R., Anderson, T., \& Archer, W. (2000). Critical inquiry in a text-based environment: Computer conferencing in higher education. The Internet and Higher 
Education, 2, 87-105.

Garrison, D. R. (2011). Article review - social presence within the community of inquiry framework. International Review of Research in Open and Distance Learning, 13(1), $250-252$.

Gorham, J., \& Christophel, D. (1990). The relationship of teachers' use of humor in the classroom to immediacy and student learning. Communication Education, 39(1), 46-62. https://doi.org/10.1080/03634529009378786.

Gunawardena, C. N. (1995). Social presence theory and implications for interaction and collaborative learning in computer conferences. International Journal of Educational Telecommunications, 1(2), 147-166.

Gunawardena, C. N., \& Zittle, F. J. (1997). Social presence as a predictor of satisfaction within a computer-mediated conferencing environment. American Journal of Distance Education, 11(3), 8-26.

Ilias and Nor, M. (2012). Influence of Teacher-Student Interaction in the Classroom Behaviour on Academic and Student Motivation in Teachers' Training Institute in Malaysia. Academic Research International, 2(1), 580-589.

Irwin, C., \& Berge, Z. (2006). Socialization in the online classroom elements of socialization that affect online education. E-Journal of Instructional Science and Technology, 9(1), 1-7.

Joksimović, S., Gašević, D., Kovanović, V., Riecke, B. E., \& Hatala, M. (2015). Social presence in online discussions as a process predictor of academic performance. Journal of Computer Assisted Learning, 31(6), 1-37. https://doi.org/10.1111/jcal.12107

Papamitsiou, Z., \& Economides, A. A. (2014). Students' perception of performance vs actual performance during computer based testing: A temporal approach. Paper presented at the 8th International Technology, Education and Development Conference, Valencia, Spain.

Picciano, A. G. (2002). Beyond student perceptions: Issues of interaction, presence, and performance in an online course. Journal of Asynchronous Learning Networks, 6(1), $21-40$.

Richardson, J. C., Maeda, Y., Lv, J., \& Caskurlu, S. (2017). Social presence in relation to students' satisfaction and learning in the online environment: A meta-analysis. $\begin{array}{llll}\text { Computers in Human } & \text { Behavior, } & \text { 41, }\end{array}$ https://doi.org/http://dx.doi.org/10.1016/j.chb.2017.02.001.

Richardson, J. C., \& Swan, K. (2003). Examining social presence in online courses in relation to students' perceived learning and satisfaction. Journal of Asynchronous Learning Network, 7(1), 68-88. https://doi.org/10.1016/j.pec.2009.03.021.

Rourke, L., Anderson, T., Garrison, D. R., \& Archer, W. (2001). Assessing social presence in asynchronous text-based computer conferencing. Journal of Distance 
Education, 11(4.2), 1-18.

Short, J., Williams, E., \& Christie, B. (1976). The social psychology of telecommunications. London: Wiley.

Sung, E., \& Mayer, R. E. (2012). Five facets of social presence in online distance education. Computers in Human Behavior, 28(5), 1738-1747.

$\mathrm{Tu}$, C.-H. (2002). The measurement of social presence in an online learning environment. International Journal on E-Learning, 1(2), 34-45.

Valenzuela, F.-R., Fisher, J., Whale, S., \& Adapa, S. (2013). Developing and evaluating social presence in the online learning environment. International Proceedings of Economics Development \& Research, 60, 95.

Wei, C.-W., \& Chen, N.-S. (2012). A model for social presence in online classrooms. Educational Technology Research and Development, 60(3), 529-545.

Wheeler, K. (2007). Mashing, burning, mixing and the destructive creativity of Web 2.0: applications for medical education. RECIIS, 1(1), 27-33.

Whiteside, A., Dikkers, A., \& Lewis, S. (2014). The power of social presence for learning. Retrieved from https://er.educause.edu/articles/2014/5/the-power-of-socialpresence-for-learning.

Yildiz, S. (2009). Social Presence in the Web-Based Classroom Implications for Intercultural. Journal of Studies in International Education, 13(1), 46-65. https://doi.org/10.1177/1028315308317654.

Zhan, Z., \& Mei, H. (2013). Academic self-concept and social presence in face-to-face and online learning: Perceptions and effects on students' learning achievement and satisfaction across environments. Computers and Education, 69, 131-138. https://doi.org/10.1016/j.compedu.2013.07.002. 